\title{
Monte Carlo-based down-scatter correction of SPECT attenuation maps
}

Tomislav Bokulić;1, 2, 3, Brendan Vastenhouw1, 2, Hugo W. A. M. de Jong ${ }^{4}$, Alice J. van Dongen¹, Peter P. van Rijk ${ }^{1}$, Freek J. Beekman ${ }^{1,2}$

1 Department of Nuclear Medicine, Image Sciences Institute, University Medical Centre Utrecht, Utrecht, The Netherlands

2 Rudolf Magnus Institute of Neuroscience, University Medical Centre Utrecht, Utrecht, The Netherlands

${ }^{3}$ Department of Oncology and Nuclear Medicine, University Hospital "Sestre milosrdnice", Zagreb, Croatia

4 VU Medical Centre, Clinical PET Centre, Amsterdam, The Netherlands

Published online: 4 September 2004

(C) Springer-Verlag 2004

Eur J Nucl Med Mol Imaging (2004) 31:1451

DOI 10.1007/s00259-004-1671-1

The online version of the original article can be found at http://dx.doi.org/10.1007/s00259-004-1507-z

Freek J. Beekman (ه)

Department of Nuclear Medicine, Image Sciences Institute, University Medical Centre Utrecht, Universiteitsweg 100, STR 5.203 Utrecht, The Netherlands

e-mail: freek@isi.uu.nl

Tel.: +31-30-2538843, Fax: +31-30-2539032

\section{Eur J Nucl Med Mol Imaging (2004)} 31:1173-1181

The name of the first author was misspelled in the print and pdf version of the article. His name is correctly spelled, Tomislav Bokulić. 